\title{
Procedure for Stacking Tile-Cal Submodules \\ Using the Argonne Designed Stacking Fixture*
}

\author{
Norman F. Hill \\ High Energy Physics Division \\ Argonne National Laboratory, Argonne, Illinois \\ RECEIVED \\ NOV 211995 \\ OSTI
}

21 July 1995

\section{Purpose}

The purpose of this fixture is to provide a general purpose tool that is simple to construct, simple to use, and flexible enough to adapt to different Tile-Cal Hadron Calorimeter submodule heights and configurations. It is also adaptable for modules that are shorter in radius, if two different lengths are necessary to accommodate the support of the liquid argon cryostat. With minor changes, this fixture can also be used to stack the proposed modules for the "Crack Filler". It is expected that minor modifications may be necessary to adapt this fixture to different facilities and working conditions. It is not presumed that this procedure will be satisfactory for every institution that will use it, and suggestions for changes to this procedure will be accepted as constructive and useful information.

\section{General Operation}

The fixture is designed to receive pre-assembled half periods, that have previously been assembled, with the adhesive applied to both the masterplate

* Work supported by the U.S. Department of Energy, Division of High Energy Physics, Contract W-31-109-ENG-38. 


\section{DISCLAIMER}

Portions of this document may be illegible in electronic image products. Images are produced from the best available original document. 
and the top surface of the spacer plates. In addition, the spring pins will have been inserted between the spacer and master plates. The master plates, with the spacer plates attached, will be stacked in the fixture using the keys at the large and small end for location. When all of the plates are stacked in the fixture, the small end bracket will be moved against the small end key surface and clamped. The top load plate is then installed, the load bars are placed, and the stack is compressed by torqueing the load screws on the load bars. The stack is then allowed to sit for 24 hours to allow the adhesive to polymerize. The weld bars are then located, clamped, and tack welded at the four corners. When welding is complete, the module is unclamped and removed from the fixture.

\section{Step-by-Step Procedure}

1. The first half period (Drawing \# TIL 305362 ) is removed from the gluing fixture after the glue has been applied, and the spacers have been pinned in place. The half period is placed on the baseplate surface of the stacking fixture (Drawing \# AT-310-1-1), positioned by placing the keyway in the master plate outer radius (large end) over the corresponding key in the fixture, and lowering over the inner radius (small end) key. This will establish the $\phi$ position of the half period.

2.

The same procedure is then repeated for the second half period. After each half period is placed in the stacking fixture, the movable small end key is pushed against the surface of the keyway in the master plate using the adjusting screw (see Drawing \# AT-310-1-0). This establishes the radial position of the half periods. After this is done, the key is then retracted to allow enough space for inserting the next half period. The key should never lose contact with the edges of the keyway because the $\phi$ location will be lost. The retraction of the key can therefore be no more than $5-7 \mathrm{~mm}$.

3. The small end spacers are then glued to the tabs at the small end, being careful to align the spacer leg to the end surface (see Drawing \# TIL 338565). 
4. The stacking of the half periods is then repeated until the full height of the module is achieved. This height varies acording to which submodule is being assembled. (see note). The standard submodule (Drawing \# TIL 305399) is the base height and the special submodules are then defined by (Drawing \# TIL 305400 and TIL 305401).

Note:

There are three different submodule dimensions that make up the six meter barrel modules, and the 2.7 meter extended barrel modules. The 6 meter module is made up of 18 standard submodules and one special module. The 2.7 meter extended barrel module consists of eight standard submodules and one special submodule.

5. When the last half period has been installed in the fixture, a set of six columns (Drawing\# AT-310-1-13 AT-310-1-41, or AT-310-1-42 ) are then selected for the correct submodule and bolted to the baseplate. These columns provide the correct dimension for the stack height and must all be the same, as identified by the stamped numbers on each column.

6. A bond sample piece of steel should have adhesive applied, and be clamped as a test for each submodule. These test samples should be allowed to cure at the same temperature and under the same conditions as the submodule. Tensile load tests will then be conducted as a measure of the quality of the adhesive bond.

7. The top load plate (Drawing \# AT-310-1-2) is placed on the stack, and the load bars (Drawing \# AT-310-1-10) and tie rods (Drawing \# AT310-1-11) are installed and adjusted for stack height. Once this has been done, the three load screws on each bar are torqued to the proper torque and the stack is allowed to set until the adhesive has polymerized usually 12-24 hours depending on the ambient temperature. 
8.

When the adhesive has fully cured, the appropriate weld bar locator is selected (Drawing \# AT-310-1-33 through 40) and attached to the end keys and the weld bars. (Drawing \# TIL 326877, TIL 326878, or TIL 326890) are selected and attached to the matching welding locator.

9.

The clamping screws are then tightened, forcing the bars against the flat surface and into the corner formed by the tab and surface. This operation is completed at both the large and small ends of the submodule.

10.

The tack welding of the bars can then proceed. When the welds have been completed, the module can be removed from the fixture and moved to the final welding location.

\section{DISCLAIMER}

This report was prepared as an account of work sponsored by an agency of the United States Government. Neither the United States Government nor any agency thereof, nor any of their employees, makes any warranty, express or implied, or assumes any legal liability or responsibility for the accuracy, completeness, or usefulness of any information, apparatus, product, or process disclosed, or represents that its use would not infringe privately owned rights. Reference herein to any specific commercial product, process, or service by trade name, trademark, manufacturer, or otherwise does not necessarily constitute or imply its endorsement, recommendation, or favoring by the United States Government or any agency thereof. The views and opinions of authors expressed herein do not necessarily state or reflect those of the United States Government or any agency thereof. 